\title{
OTOMASI SISTEM HIDROPONIK DFT (DEEP FLOW TECHNIQUE) BERBASIS ARDUINO ANDROID DENGAN MEMANFAATKAN PANEL SURYA SEBAGAI ENERGI ALTERNATIF
}

\author{
Eko Agus Suprayitno ${ }^{1}$, Rohman Dijaya ${ }^{2}$, M. Atho'illah ${ }^{3}$ \\ 1,2,3 Universitas Muhammadiyah Sidoarjo \\ E-mail: eko.agus@umsida.ac.id
}

\begin{abstract}
The application of hydroponic farming methods has been widely applied by the community, the system used is still manual so that it lacks quality, both in terms of humidity and growth. For that we need a system that is able to regulate the time of watering and the provision of nutritional solutions automatically without disturbing the activity. In the design of an automatic DFT hydroponic system using an Android Arduino based solar panel. Where the solar panel system functions as a renewable energy substitute for PLN which will fill the accumulator. The accumulator filling process is equipped with a solar charge controller module, which aims to avoid overcharging the accumulator. The process of watering and administering nutritional solutions is controlled by the Arduino UNO microcontroller which is integrated with the DS1307 RTC module, the HC-05 bluetooth serial communication module and the android smartphone application as the relay module to turn on and turn off the circulation pump according to a predetermined schedule. Test results and tool performance are in accordance with the plan, namely the efficiency of the use of solar panels. This is indicated by scheduling the circulation of the circulating pump for 1 hour from the estimated calculation of the maximum pump speed for 2.38 hours. In testing the transmission of data from bluetooth HC-05 connected to a bluetooth smartphone with unhindered conditions obtained a maximum distance of 15 meters and with a concrete wall obstruction a maximum distance of 5 meters, with plywood walls a maximum distance of 8 meters.
\end{abstract}

Keywords: Hydroponic , Android, Arduino, DFT System.

\section{PENDAHULUAN}

Hidroponik merupakan cara budidaya tanaman tanpa menggunakan media tanah, dengan pengganti medianya seperti gravel, peat, vermikulit, sawdust yang dibantu dengan unsur hara yang diperlukan tanaman untuk tumbuh dan berkembang[1]. Hidroponik penerapannya banyak dilakukan oleh masyarakat hingga saat ini, hanya saja masih dilakukan secara manual baik dari sisi kontrol kelembapan, kandungan, nutrisinya, serta aliran airnya yang dilakukan secara terus menerus sehingga boros akan listrik.

Pernah dilakukan penelitian tentang irigasi tanaman menggunakan energi surya untuk irigasi tanaman. Pada penelitian ini panel surya berfungsi sebagai pembangkit untuk mengisi akumulator, pompa DC untuk mengisi tandon yang dilengkapi sensor ketinggian air yang akan mematikan pompa saat tendon air sudah terisi penuh. Proses penyiraman dilakukan secara otomatis ketika kelembaban tanah pada tanaman telah berkurang. Pada sistem ini dilengkapi solar charge controller yang otomatis mengisi tenaga akumulator yang memiiki tegangan $11,6 \mathrm{~V}$ dan mematikan pengisian ketika tegangan akumulator 13,4 V [4].

Berdasarkan referensi penelitian yang sudah ada, maka pada penelitiian ini dilakukan rancang bangun Otomasi system Hidroponik DFT (Deep Flow Technique) berbasis Arduino dan Android, dengan memanfaatkan energi Surya sebagai sumber tegangan Otomasi alatnya. Penelitian ini dilakukan dengan tujuan agar proses pemberian larutan nutrisi dan sirkulasi perputaran airnya dengan pompa air berjalan otomatis, terjadwal, dan efisien. Mikrokontroller yang digunakan adalah Arduino uno sebagai kontrolnya, komunikasi antara hardware dengan androidnya 
menggunakan Bluetooth HCO5, aplikasi androidnya dibuat dengan software MIT App Inventor, modul RTC yang terintegrasi dengan modul bluetooth HC-05 dan smartphone android akan memberi perintah modul relay untuk menyalakan dan mematikan pompa penyiraman. dan sumber tegangan Otomasi alat pada penelitian ini menggunakan Energi matahari.

\section{TINJAUAN PUSTAKA}

Berdasarkan studi literatur terkait penelitian yang mendukung, dihasilkan beberapa resume kesamaan maupun perbedaan mendasar akan penelitian yang sudah dilakukan dengan penelitian yang penulis angkat, diantaranya dijelaskan sebagai berikut.

Pernah dilakukan oleh Yasir Arafat tahun 2015 tentang otomasi aliran pompa tanaman hidroponik berdasarkan kelembapan media tanam Hidroponik, dan memanfaatkan Energi Surya sebagai sumber tegangan pompanya. Pada prinsipnya ketika kelembapan yang diharapkan terpenuhi, maka pompa secara otomatis akan menyala dan mengalirkan air pada tanaman Hidroponik. Mikrokontroller yang digunakan adalah ATmega 8535.

Terkait penelitian hidroponik juga pernah dilakukan oleh tentang Otomasi Sistem Hidroponik Pasang Surut Untuk Budidaya Tanaman Cabai. Penyiraman otomatis akan meyala ketika kelembapan yang terbaca $<34,49$ $\%$, dan otomatis mati pada kelembaban $>69,83 \%$. Sensor kelembapan yang digunakan adalah moisture sensor, sensor suhu digunakan untuk membaca suhu yang terbaca disekitar tanaman, Mikrokotroller yang digunakan Arduino Uno.

Sedangkan penelitian yang penulis lakukan adalah rancang bangun Otomasi system Hidroponik DFT (Deep Flow Technique) berbasis Arduino dan Android, dengan memanfaatkan energi Surya sebagai sumber tegangan Otomasi alatnya. Penelitian ini dilakukan dengan tujuan agar proses pemberian larutan nutrisi dan sirkulasi perputaran airnya dengan pompa air berjalan otomatis, terjadwal, dan efisien. Mikrokontroller yang digunakan adalah Arduino uno sebagai kontrolnya, komunikasi antara hardware dengan androidnya menggunakan Bluetooth HCO5, aplikasi androidnya dibuat dengan software MIT App Inventor, modul RTC yang terintegrasi dengan modul bluetooth HC-05 dan smartphone android akan memberi perintah modul relay untuk menyalakan dan mematikan pompa penyiraman. dan sumber tegangan Otomasi alat pada penelitian ini menggunakan Energi matahari.

\section{METODE}

Diagram blok system keseluruhan rancang bangun Otomasi system Hidroponik DFT (Deep Flow Technique) berbasis Arduino dan Android, dengan memanfaatkan energi Surya sebagai sumber tegangan Otomasi diperlihatkan pada gambar berikut.

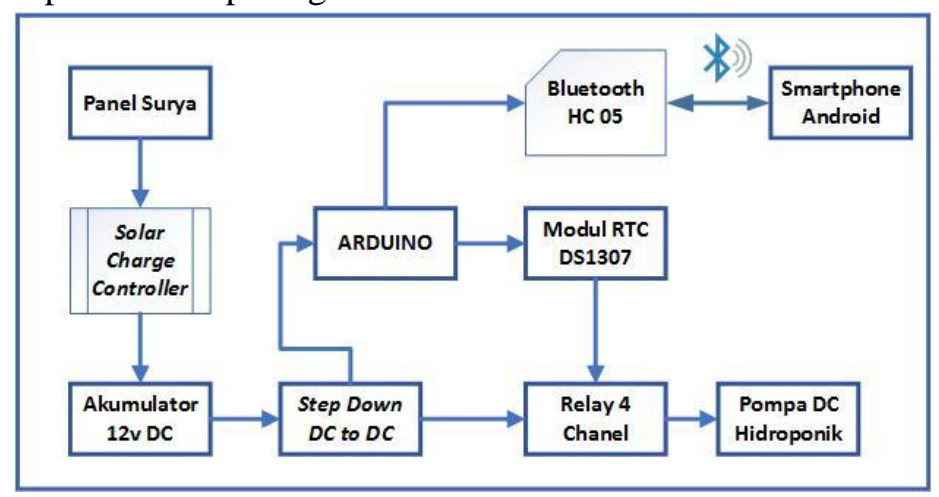

Gambar 3.1 Diagram Blok system rancang bangun Otomasi system Hidroponik DFT (Deep Flow

Technique) berbasis Arduino dan Android dengan panel surya

Penjelasan diagram blok secara rinci dipaparkan sebagai berikut ini.

1. Panel surya berfungsi sebagai penangkap radiasi sinar matahari yang kemudian akan diubah menjadi sumber energi listrik.

2. Fungsi dari modul RTC DS1307 adalah sebagai kontrol waktu penjadwalan proses nyala dan mati pompa sirkulasi..

3. Tegangan masukan dari panel surya akan masuk ke dalam mdul solar charge controller. Fungsi dari modul ini adalah sebagai pemutus otomatis pada saat 
pengisian baterai, agar baterai tidak cepat rusak dikarenakan pengisian tegangan yang terus menerus.

4. Akumulator $12 \mathrm{~V}$ berfungsi sebagai penyimpan energi listrik dari panel surya.

5. Modul DC to DC stepdown berfungsi sebagai penurun tegangan dari akumulator $12 \mathrm{~V}$ menjadi tegangan $5 \mathrm{~V}$ yang digunakan sebagai tegangan masukan pada arduino, modul relay 4 channel dan juga Bluetooth HC-05.

6. Arduino berfungsi sebagai kontroler semua sistem keseluruhan yang akan dibuat.

7. Modul relay 4 channel berfungsi sebagai saklar otomatis yang mengontrol perintah dari arduino yang berupa logika High yang akan menyalakan pompa penyiraman.

8. Bluetooth HC-05 berfungsi sebagai komunikasi serial antara smartphone android dengan arduino melalui aplikasi yang telah dibuat melalui software MIT APP inventor 2.

9. Pompa sirkulasi berfungsi sebagai pendistribusi larutan nutrisi dari tandon menuju ke talang - talang dan kembali lagi ke tandon.

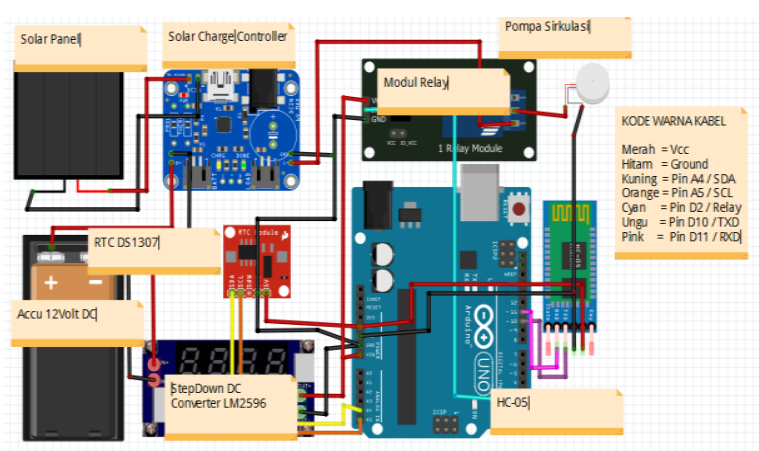

Gambar 3.2 Rangkaian Komponen keseluruhan Otomasi system Hidroponik DFT (Deep Flow

Technique) berbasis Arduino dan Android dengan panel surya

Pada perancangan desain hidroponik sistem DFT otomatis terdiri dari Rangkaian pipa PVC yang akan dipersiapkan sebagai media hidroponik, Pipa Penyangga, box panel kontrol untuk melindungi komponen komponen dari berbagai gangguan. Gambar desain keseluruhan hidroponik sistem DFT otomatis dapat dilihat pada Gambar 3.3.

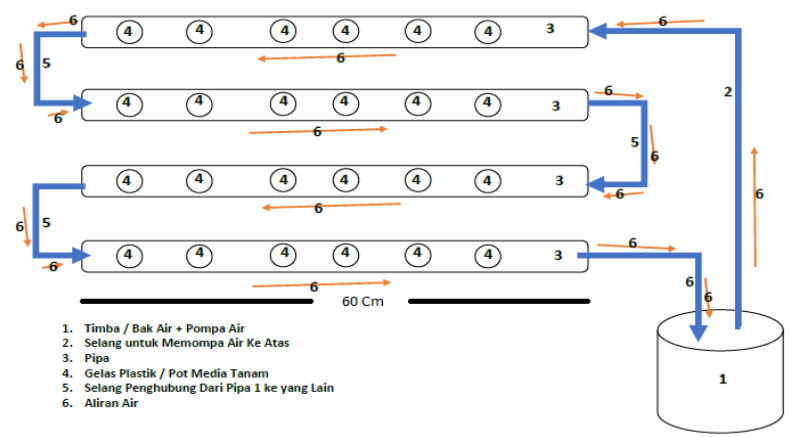

Gambar 3.3 Desain Tampak Atas Media Hidroponik yang akan dibuat

Gambar Desain Penyangga Media Hidroponik Dilihat Dari Samping dapat dilihat pada Gambar 3.4.

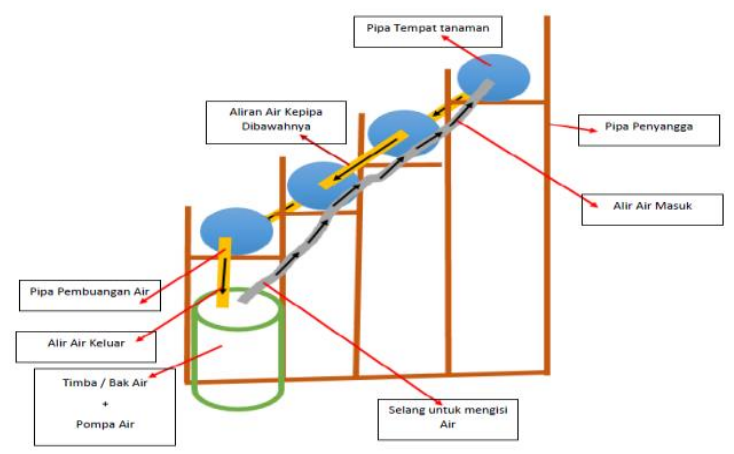

Gambar 3.4 Desain Penyangga Media Hidroponik Dilihat Dari Samping

Berikut penjelasan dari masing - masing bagian:

1. Rangkaian Pipa PVC

Digunakan sebagai tempat media tanam (Netpot) dan sirkulasi larutan nutrisi.

2. Pipa Penyangga

Digunakan sebagai penyangga agar media tanam yang terbuat dari rangkaian pipa PVC tidak mengalami goncangan.

\section{Box Kontrol}

Digunakan sebagai tempat kontroler semua komponen penyusun sistem.

Prosedur pengujian dilakukan agar bisa didapatkan hasil yang akurat dan tepat jika dibandingkan dengan alat standar industry maupun standar yang sudah ada. Pengujian 
yang dilakukan pada penelitian ini antara lain dilakukan sebagai berikut.

1. Pengujian panel surya dilakukan untuk mengetahui tegangan yang dihasilkan dari pagi hingga sore hari guna untuk mengetahui waktu optimal saat proses charging

2. Pengujian Panel Surya Dengan Modul Solar Charge Controller. Pengujian ini dilakukan untuk mengetahui tegangan input panel surya yang masuk ke dalam akumulator 12 VDC. Tujuan pemasangan Modul ini agar tegangan dari panel surya dapat terkontrol dengan baik ketika proses charging dan discharging, sehingga kondisi akumulator tetap prima

3. Pengujian Proses Charge Dan Discharging. Pengujian proses charging dan discharging dilakukan untuk mengetahui kinerja komponen - komponen yang berperan untuk memberikan supply tenaga listrik pada sistem yang akan dibuat.

4. Pengujian Modul RTC DS 1307 Dan Modul Relay. Pengujian ini dilakukan untuk mengetahui apakah modul RTC (Real Time Clock) dan modul relay dapat bekerja dengan baik saa diintegrasikan dengan smartphone android sesuai dengan yang diinginkan

\section{HASIL DAN PEMBAHASAN}

Media hidroponik menggunakan material pipa PVC ukuran 2,5" dengan panjang 1 meter sebanyak 4 tingkat sebagaimana Gambar berikut. Panel Surya yang digunakan $20 \mathrm{wp}$, degan pompa air menggunakan tegangan DC 12 Volt.

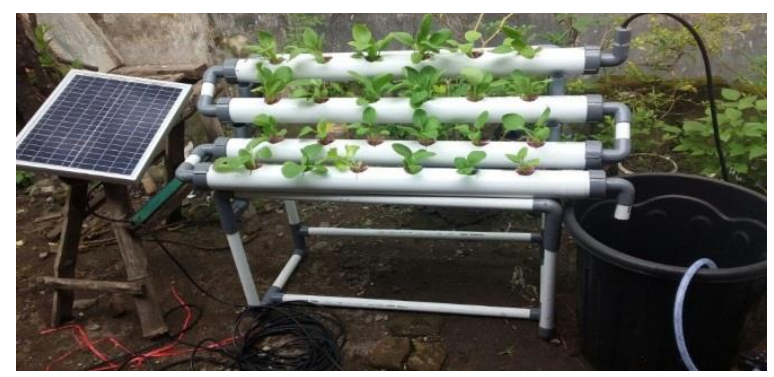

Gambar 4.1. Media Hidroponik DFT Yang Telah Dibuat

Pengujian yang dilakukan pada penelitian ini antara lain dilakukan sebagai berikut.

1. Pengujian panel surya dilakukan untuk mengetahui tegangan yang dihasilkan dari pagi hingga sore hari guna untuk mengetahui waktu optimal saat proses charging.

Tabel 4.1 Pengujian Panel Surya

\begin{tabular}{|c|c|c|c|c|c|c|}
\hline \multirow{2}{*}{ No. } & \multirow{2}{*}{$\begin{array}{c}\text { Jadwal } \\
\text { Sirkulasi }\end{array}$} & \multicolumn{3}{|c|}{ Pengujian ke- (v) } & \multirow{2}{*}{$\begin{array}{c}\text { Rata- } \\
\text { Rata (v) }\end{array}$} & \multirow{2}{*}{$\begin{array}{c}\text { Standard } \\
\text { Deviasi }\end{array}$} \\
\hline & & 1 & 2 & 3 & & \\
\hline 1 & 06.00 & 18 & 18.5 & 18.6 & 18.3 & 0.3 \\
\hline 2 & 09.00 & 18 & 18 & 18 & 18 & 0 \\
\hline 3 & 12.00 & 20 & 20 & 20 & 20 & 0 \\
\hline 4 & 15.00 & 19 & 19 & 19 & 19 & 0 \\
\hline 5 & 18.00 & 0 & 0 & 0 & 0 & 0 \\
\hline
\end{tabular}

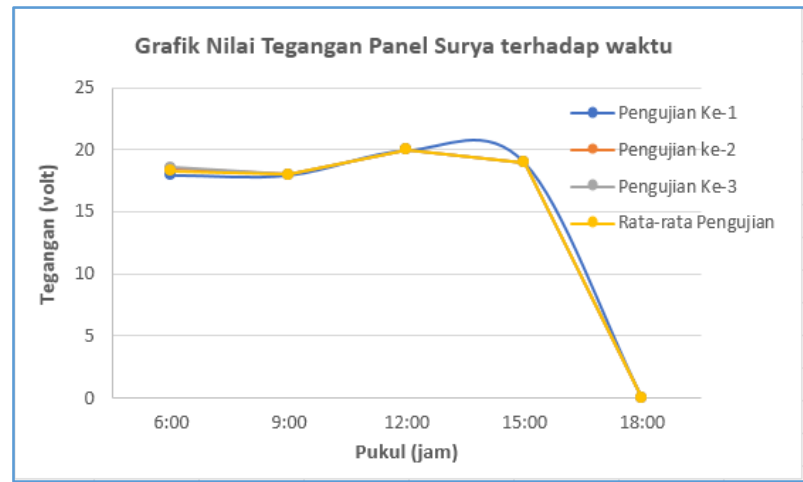

Gambar.4.2. Grafik Nilai tegangan Panel Surya terhadap Waktu

Dimana : $\frac{\mu=\frac{x_{1}+x_{2}+x_{3} \ldots+x_{n}}{\mathrm{n}}}{\sigma=\sqrt{\frac{\sum_{i=1}^{n}\left(x_{i}-\mu\right)^{2}}{n}}}$

Keterangan : $\mu=$ Nilai Rata-rata

$\sigma=$ Standard Deviasi

$\mathrm{n}=$ Banyaknya data

$x_{1}=$ Data ke -1

$x_{n}=$ Data ke-n

$x_{i}=$ Data ke- $\mathrm{i}$ 
Berdasarkan table didapatkan data bahwa pada pukul 06.00 menunjukkan hasil tegangan panel surya yang berbeda. Hal ini dipengaruhi oleh beberapa faktor diantaranya intensitas cahaya, mendung dan lain - lain. Waktu yang paling optimal untuk melakukan proses charging adalah pada rentang waktu pukul $09.00-15.00$. Berdasarkan gambar grafik diatas menunjukkan adanya penurunan tegangan antara pukul 15.00 - 18.00. Kondisi ini terjadi dikarenakan faktor intensitas cahaya matahari yang masuk ke dalam panel surya berkurang. Sehingga tegangan yang diukur sebesar 0 V. Hasil Analisa standar deviasi menunjukkan nilai standar deviasi yang sangat kecil, hal tersebut menginformasikan bahwa hasil pengujian yang dilakukan berulang kali menghasilkan nilai yang stabil dan minim simpangan.

2. Pengujian Panel Surya Dengan Modul Solar Charge Controller. Pengujian ini dilakukan untuk mengetahui tegangan input panel surya yang masuk ke dalam akumulator 12 VDC. Tujuan pemasangan Modul ini agar tegangan dari panel surya dapat terkontrol dengan baik ketika proses charging dan discharging, sehingga kondisi akumulator tetap prima.

Tabel 4.2 Pengujian Panel Surya Dengan Modul Solar Charge Controller

\begin{tabular}{|c|c|c|c|c|c|c|}
\hline \multirow{2}{*}{ No } & \multirow{2}{*}{$\begin{array}{l}\text { Jadwal } \\
\text { Sirkulasi }\end{array}$} & \multicolumn{3}{|c|}{ Pengujian ke- } & \multirow{2}{*}{$\begin{array}{l}\text { Rata- } \\
\text { Rata }\end{array}$} & \multirow{2}{*}{$\begin{array}{c}\text { Standard } \\
\text { Deviasi }\end{array}$} \\
\hline & & 1 & 2 & 3 & & \\
\hline 1 & 06:00 & 12.5 & 12.5 & 12.5 & 12.5 & 0 \\
\hline 2 & 09:00 & 12.5 & 12.5 & 12.5 & 12.5 & 0 \\
\hline 3 & $12: 00$ & 12.5 & 12.5 & 12.5 & 12.5 & 0 \\
\hline 4 & $15: 00$ & 12.5 & 12.5 & 12.5 & 12.5 & 0 \\
\hline 5 & 18:00 & 0 & 0 & 0 & 0 & 0 \\
\hline
\end{tabular}

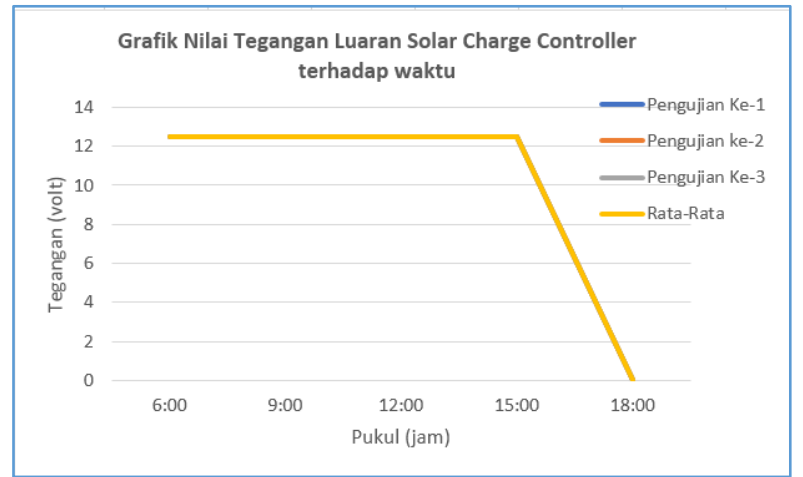

Gambar. 4.3. Grafik Nilai tegangan Luaran Solar

Controller terhadap Waktu.

Berdasarkan grafik diatas menunjukkan tren nilai yang stabil mulai dari pukul 06.00 - 15.00, hal ini menunjukkan bahwa tegangan yang masuk ke dalam akumulator stabil. Efek dari kestabilan tegangan yang masuk ke dalam akumulator akan menjaga kondisi akumulator tetap prima.

3. Pengujian Proses Charge dan Discharging. Pengujian proses charging dan discharging dilakukan untuk mengetahui kinerja komponen - komponen yang berperan untuk memberikan supply tenaga listrik pada sistem yang akan dibuat. Perhitungan dilakukan berdasarkan datasheet masing masing komponen. Pada bagian penyimpan tenaga listrik DC digunakan sebuah akumulator 12 VDC merk PANASONIC yang memiliki kuat arus 7,2 Ah. Untuk mengontrol tegangan dan mengantisipasi overcharging pada akumulator, maka diperlukan sebuah modul solar charge controller. Gambar akumulator dapat dilihat pada Gambar 4.4.

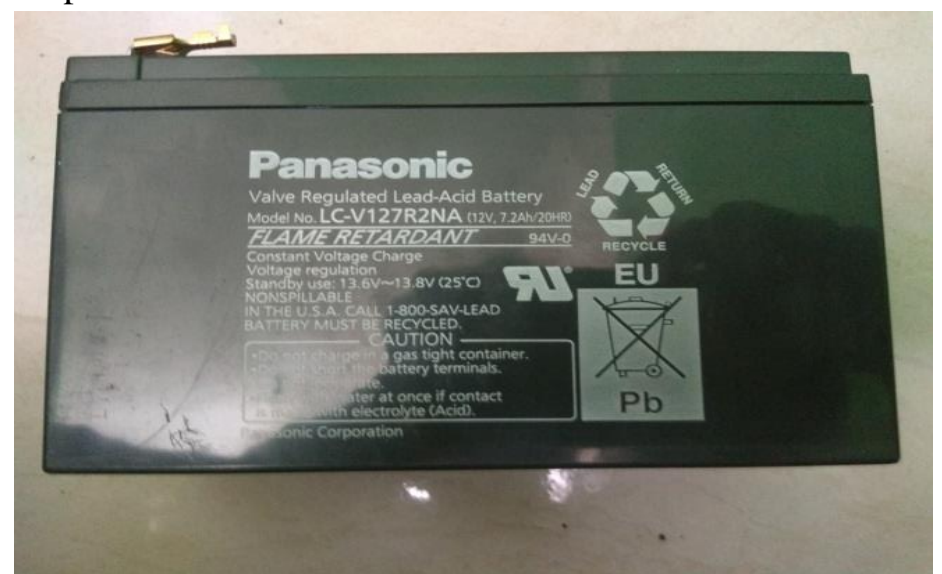


Gambar 4.4 Akumulator PANASONIC 12 VDC

Pada Gambar 4.4 menunjukkan bahwa penggunaan akumulator merk PANASONIC 12 VDC dengan rating arus 7,2 Ah. Untuk mengetahui besaran daya akumulator dapat dihitung dengan persamaan dibawah ini :

Diketahui :

$$
\begin{aligned}
\mathrm{V} & =12 \text { Volt } \\
\mathrm{I} & =7,2 \mathrm{Ah}
\end{aligned}
$$

Jadi perhitungan daya akumulator :

$$
\begin{aligned}
\mathrm{P} & =\mathrm{V} \times \mathrm{I} \\
& =12 \text { Volt } \times 7,2 \mathrm{Ah} \\
& =86,4 \text { Watt }
\end{aligned}
$$

Jadi daya yang tersimpan dalam akumulator sebesar 86,4 Watt. Untuk mengoptimalkan, memperpanjang usia akumulator, dan untuk proses pemakaian (discharging) serta pengisian (charging), maka diperlukan modul solar charge controller. Gambar modul solar charge controller dapat dilihat pada Gambar 4.5.

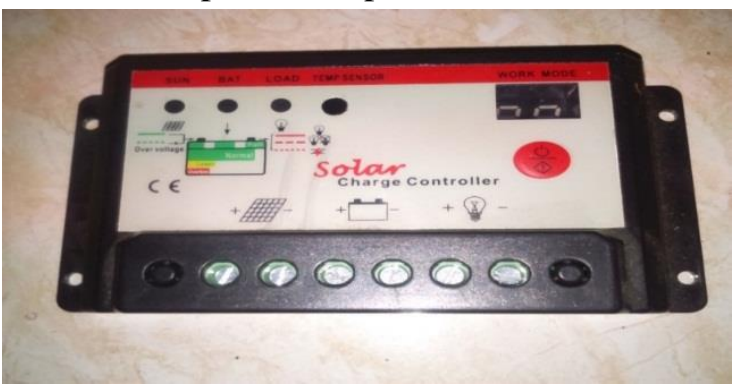

Gambar 4.5 Modul Solar Charge Controller

Gambar datasheet modul Solar Charge

Controller dapat dilihat pada Gambar 4.6.

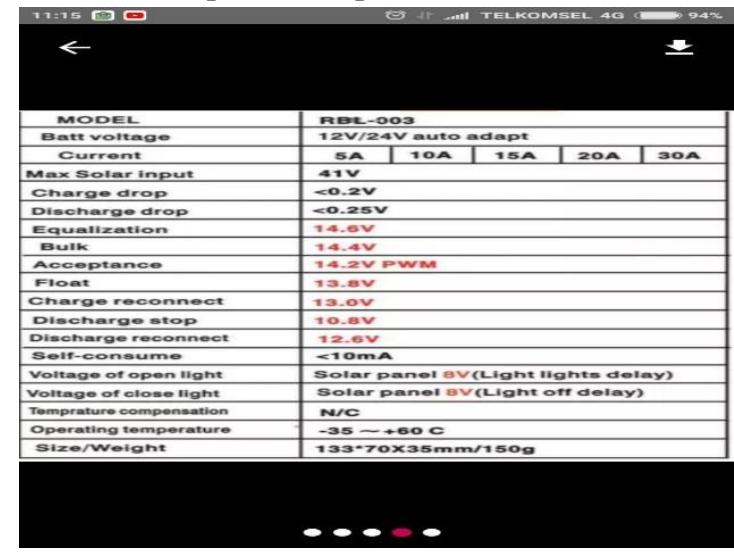

Gambar 4.6 Datasheet Modul Solar Charge

Controller

Gambar instalasi modul Solar Charge Controller pada box panel dapat dilihat pada Gambar 4.7.

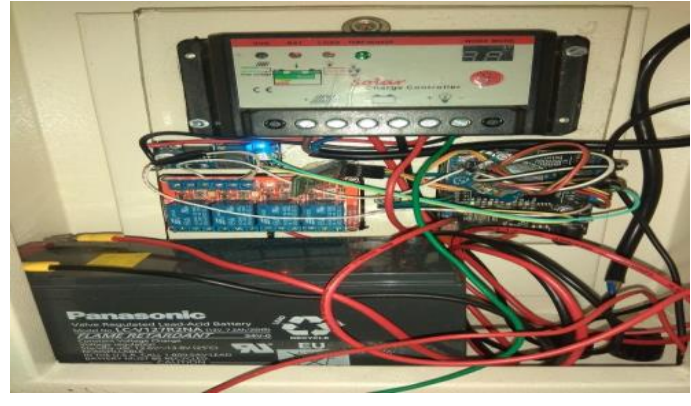

Gambar 4.7 Instalasi Modul Solar Charge Controller Pada Box Panel

Pada Gambar 4.5 merupakan bentuk dari modul solar charge controller tipe PWM. Adapun instalasi pemasangannya ditunjukkan pada Gambar 4.7. Fungsi utama dari pemasangan modul solar charge controller adalah untuk mengontrol dan menstabilkan tegangan yang masuk dari panel surya ke dalam akumulator ketika proses charging. Kemudian melakukan auto cut off untuk menghindari overcharging pada akumulator.

Pada proses charging atau pengisian akumulator menggunakan 1 buah panel surya dengan kapasitas 20 wp. Gambar spesifikasi modul panel surya dapat dilihat pada Gambar 4.8 .

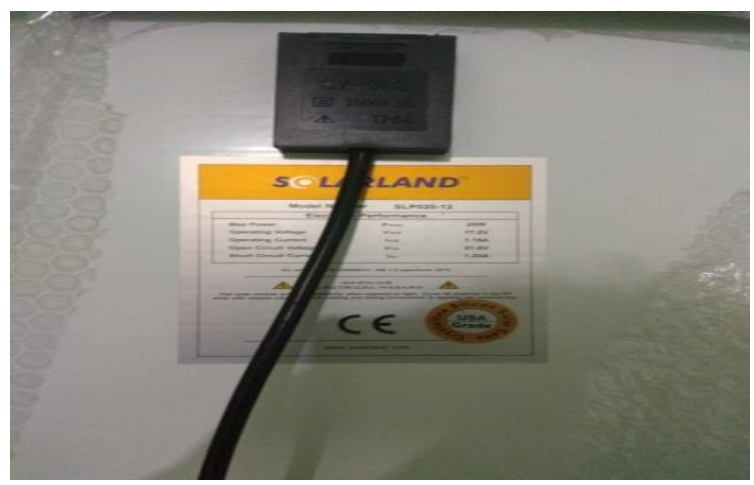

Gambar 4.8 Modul Panel Surya 20 Wpp

Pada estimasi proses charging atau pengisian baterai mengacu pada tegangan operasi didalam spesifikasi panel surya diatas dikarenakan faktor cuaca yang tidak menentu.

Diketahui :

Tegangan Panel surya dengan modul Solar Charge Controller $=12,5$ Volt, Arus Solar Panel $=1,18$ Amper

Perhitungan Daya Panel Surya:

$\mathrm{P}=\mathrm{V}$ Panel Surya dengan modul Solar Charge Controller x I Solar Panel

$$
=12,5 \mathrm{~V} x 1,18 \mathrm{~A}
$$


$=14,75 \mathrm{watt} / \mathrm{jam}$

Jadi lama proses Charging adalah:

$=\mathrm{P}$ akumulator : $\mathrm{P}$ Panel surya dengan

modul

\section{Solar Charge Controller}

$=86,4$ watt $: 14,75$ watt $/ \mathrm{jam}$

$=5,85 \mathrm{jam}$

Jadi dapat dilihat dari perhitungan waktu pengisian akumulator sampai penuh sekitar 5,85 jam tergantung dari faktor alam dan cuaca seperti mendung dn lain - lain. Pada proses discharging atau pemakaian daya baterai untuk menghidupkan pompa dengan daya 36,2

Watt dapat dilihat pada Gambar 4.9.

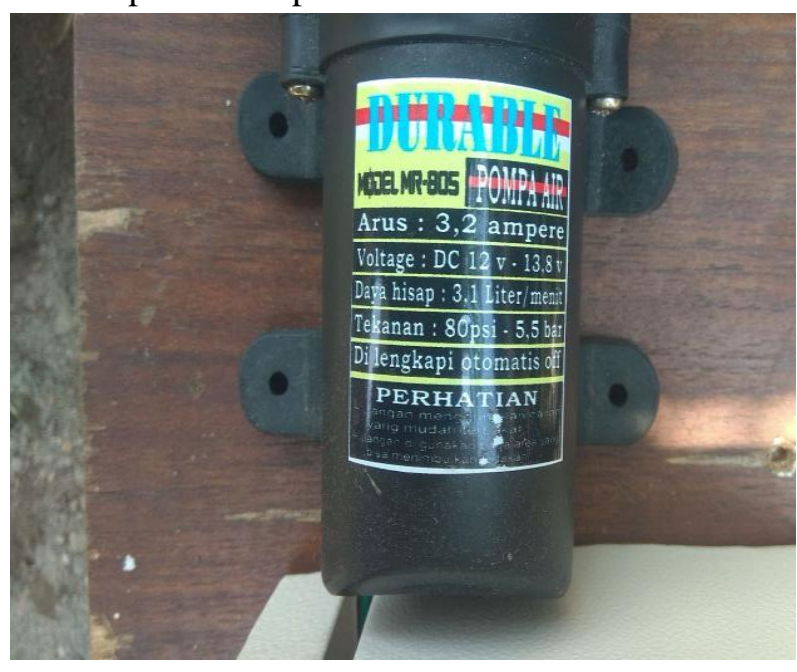

Gambar 4.9. Spesifikasi Pompa DC

Estimasi perhitungan konsumsi daya untuk menghidupkan pompa ini adalah :

Diketahui :

Lama Pompa menyala $=$ PAkumulator $:$ PPompa

$$
\begin{aligned}
& =86,4: 36,2 \text { watt } \\
& =2,38 \mathrm{jam}
\end{aligned}
$$

Jadi dari perhitungan baterai tersebut mampu menyalakan pompa selama 2,38 jam.

4. Pengujian Pengujian Sistem Keseluruhan.

Pengujian ini dilakukan untuk mengetahui

Kinerja

Otomasi Sistem Hidroponik peneliti.

\begin{tabular}{|c|c|c|c|c|}
\hline $\begin{array}{l}\mathrm{N} \\
\mathrm{o}\end{array}$ & $\begin{array}{c}\text { Jadwal } \\
\text { Sirkulasi }\end{array}$ & $\begin{array}{l}\text { Android } \\
\text { (Hidup } \\
\text { atau mati) }\end{array}$ & $\begin{array}{c}\text { Modul } \\
\text { Relay } \\
\text { ( High atau } \\
\text { Low) }\end{array}$ & $\begin{array}{c}\text { Pompa } \\
\text { (Menyala } \\
\text { atau mati) }\end{array}$ \\
\hline 1 & 6 & Hidup & High & Menyala \\
\hline
\end{tabular}

Tabel 4.3 Tabel pengujian keseluruhan sistem

\begin{tabular}{ccccc}
2 & 9 & Hidup & High & Menyala \\
3 & 12 & Hidup & High & Menyala \\
4 & 15 & Hidup & High & Menyala \\
5 & 18 & Hidup & High & Menyala \\
\hline
\end{tabular}

Berdasarkan pada Tabel pengujian 4.3 diatas dari 5 pengujian pada jam yang berbeda menunjukkan bahwa semua sistem yang telah dirancang berfungsi dengan baik dengan tingkat akurasi juga tergolong bagus. Hal ini ditunjukkan oleh data pengujian pada jam yang berbeda.

\section{KESIMPULAN}

Setelah dilakukan proses pengujian dan pengambilan data selama beberapa kali, maka pada Sistem Rancang Bangun Sistem Hidroponik DFT (Deep Flow Technique) Otomatis Menggunakan Panel Surya Berbasis Arduino Android di area kampus 2 UMSIDA dapat disimpulkan sebagai berikut :

1. Efisiensi penggunaan tenaga panel surya pada sistem hidroponik DFT (Deep Flow Technique) otomatis yang telah menunjukkan hasil yang sesuai dengan perencanaan, yaitu pompa sirkulasi menyala selama 1 jam dari total estimasi perhitungan nyala pompa maksimal 2,38 jam.

2. Aplikasi timer nyala pompa otomatis berbasis android bekerja sesuai dengan perencanaan, sehingga untuk melakukan penjadwalan ulang tidak perlu mengubah program pada mikrokontrollernya, cukup dengan smartphone android.

\section{DAFTAR PUSTAKA}

[1] F. D. Atmaja, Analisis Keseimbangan Pada Bak Penanaman Dalam Sistem Hidroponik Deep Flow Technique (DFT). 2009

[2] Delya, B.,Tusi, A., Lanya, B., \& Zulkarnain, I. (2014). Design of Ebb and Flow Automatic Hydroponic System for Chilli Pepper Cultivation. Jurnal FP Unila, 3(3), $205-212$.

[3] Y. Arafat, Penyiram Tanaman Hidroponik Otomatis Menggunakan 
Tenaga Surya Berbasis Mikrokontroler. 2015

[4] Wulandari, P., Studi, P., Elektro, T., Teknik, F., \& Surakarta, U. M. RANCANG BANGUN PROTOTIPE SISTEM POMPA AIR MENGAMBANG BERTENAGA SURYA UNTUK IRIGASI. 2014

[5] Karno, I., Sc, M. A., \& Ph, D. Workshop hidroponik. 2017

[6] B. Yuwono, Optimalisasi Panel Sel Surya dengan menggunakan sistem pelacak berbasis mikrokontroler AT89C51. 2005.

[7] [5] W. M. A. B. W. M. KAMAL, DEVELOPMENT OF ACADEMIC ATTENDANCE MANAGEMENT SYSTEM USING BLUETOOTH TECHNOLOGY, vol. 16. 2015.

[8] DALLAS Semiconductor. Ds1307, 112. Retrieved from https://www.futurlec.com/ICDallas.shtm 1. 2015

[9] UMI AZIZAH, SINTESIS GRAFIT TERLAPISI KARBON ( Citric Acid) DENGAN VARIASI KOMPOSISI SEBAGAI BAHAN ANODA PADA BATERAI ION LITHIUM. 2016.

[9] Ningrum, D. Y., Triyono, S., \& Tusi, A. PENGARUH LAMA AERASI TERHADAP PERTUMBUHAN DAN HASIL TANAMAN SAWI ( Brassica juncea L .) PADA HIDROPONIK DFT ( Deep Flow Technique ) [ THE EFFECT OF AERASION DURATION ON GROWTH AND YIELD OF GREEN MUSTARD ( Brassica junce L .) ON DFT ( Deep Flow Technique ), 3(1), 83-90. 2014

[10] R. H. Muhammad, R. S. Adi, and A. Kondisi, "Rancang Bangun Sistem Pengamanan Mobil Menggunakan ID Card Dengan Metode Radio Frequency Identification," vol. 1, no. 1, pp. 39-44, 2017. 